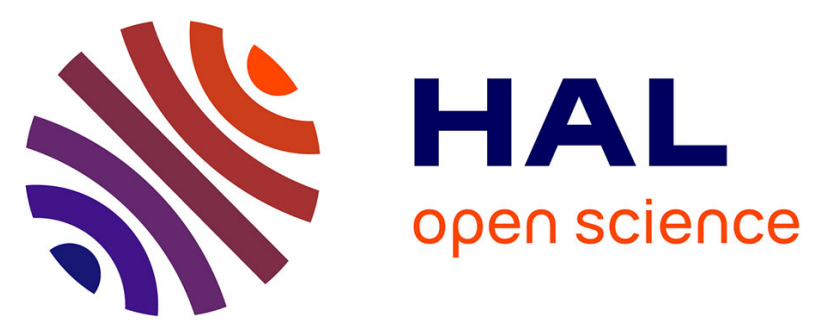

\title{
The spin-crossover phenomenon at the coherent-domains scale in 1D polymeric powders: evidence for structural fatigability
}

\author{
Arnaud Grosjean, Nathalie Daro, Stanislav Pechev, Lucie Moulet, Céline \\ Etrillard, Guillaume Chastanet, Philippe Guionneau
}

\section{To cite this version:}

Arnaud Grosjean, Nathalie Daro, Stanislav Pechev, Lucie Moulet, Céline Etrillard, et al.. The spincrossover phenomenon at the coherent-domains scale in 1D polymeric powders: evidence for structural fatigability. European Journal of Inorganic Chemistry, 2016, Advanced Complex Inorganic Nanomaterials (Cluster Issue), 13-14, pp.1961-1966. 10.1002/ejic.201501164 . hal-01319386

\section{HAL Id: hal-01319386 https://hal.science/hal-01319386}

Submitted on 3 Mar 2021

HAL is a multi-disciplinary open access archive for the deposit and dissemination of scientific research documents, whether they are published or not. The documents may come from teaching and research institutions in France or abroad, or from public or private research centers.
L'archive ouverte pluridisciplinaire $\mathbf{H A L}$, est destinée au dépôt et à la diffusion de documents scientifiques de niveau recherche, publiés ou non, émanant des établissements d'enseignement et de recherche français ou étrangers, des laboratoires publics ou privés. 


\title{
The spin-crossover phenomenon at the coherent-domains scale in 1D polymeric powders: evidence for a structural fatigability
}

\author{
Arnaud Grosjean ${ }^{[a]}$, Nathalie Daro ${ }^{[a]}$, Stanislav Pechev ${ }^{[a]}$, Lucie Moulet ${ }^{[a]}$, Céline Etrillard ${ }^{[a]}$, Guillaume \\ Chastanet $^{[\mathrm{a}]}$ and Philippe Guionneau ${ }^{[\mathrm{a}] *}$
}

\begin{abstract}
The coherent-domain morphology has been determined for a crystalline powder of the 1D polymeric spin-crossover $\left[\mathrm{Fe}(\mathrm{Htrz})_{2}(\mathrm{trz})\right]\left(\mathrm{BF}_{4}\right)$ compound. This morphology is in adequacy with the crystal packing proving that the long axis of the domain corresponds to the iron-triazole chains axis giving information on the crystal growth process. Furthermore, thermal cycling clearly demonstrates that the coherent-domain length strongly and continuously decreases as a function of the number of spin-crossover undergone. The degradation of the crystalline quality corresponds to a break in the $\left[\mathrm{Fe}(\mathrm{Htrz})_{2}(\mathrm{trz})\right]^{+}$chains. This structural fatigability is confirmed by similar observations on a close spin-crossover compound, $\left[\mathrm{Fe}\left(\mathrm{NH}_{2} \mathrm{trz}\right)_{3}\right]\left(\mathrm{NO}_{3}\right)_{2} \cdot \mathrm{H}_{2} \mathrm{O}$, showing that a few hundreds of thermal spin-crossover could destroy the crystalline aspect of the sample.
\end{abstract}

\section{Introduction}

The spin-crossover phenomenon, denoted SCO, appears more than ever investigated by a very large scientific community resulting in an increasing number of published results that have notably in common to illustrate the complexity of the SCO in the solid state. ${ }^{[1]}$ The SCO, i.e. the switch between the High Spin (HS) state and the Low Spin (LS) state of a coordination metal induced by an external stimulus, is by essence a purely atomic-scale phenomenon. But since in a solid state the atoms are never isolated, the modifications due to the SCO at the atomic scale impact the whole sample scales. The mechanism and the amplitude of the modifications that affect the solid correspond to a wide panel of situations based on some general trends but it is also shown that almost every SCO material reveals ultimately to be peculiar. The general trends concern essentially the modification of the metal coordination sphere - same amplitude of metal-ligand bond lengths, distortion and volume changes - while the modifications of the molecular interactions, i.e. of the crystal packing in a crystalline solid, appear always different from one compound to another causing intricate phase diagrams. The latter generally differ from one SCO compound to another even when complexes are chemically close. ${ }^{[2]}$ The structure-property relationship is particularly noticeable at any physical scale in the SCO solids and consequently, the SCO properties such as the temperatures of transition, the hysteresis width or the conversion rate appear different for every compound, explaining partially the infatuation for the study of these materials. Figure 1 summarizes the multiscale understanding of the propagation of the SCO phenomenon in the crystalline state. In parallel to the physical scales, the time-scale of the SCO phenomenon has been investigated in crystals showing some counterintuitive behaviors such as the relatively long interval of time between the metal coordination sphere and the unit cell expansions. ${ }^{[3]}$ Figure 1 includes some references to the time scale but the core of this article addresses the physical multiscale description of the SCO phenomenon. Innumerable studies focusing on the molecular and the crystal-packing scales have been performed over the last thirty years resulting in a deep understanding of the SCO effects at these levels within the solid. Even though it can be considered quite late in the SCO investigation history, the propagation of the SCO at the scale of the crystal itself is presently focusing many attentions revealing a beautiful face of this phenomenon in particular when investigated by mean of optical microscopy. ${ }^{[4]} \mathrm{On}$ the contrary, the physical scale that lays in between the crystal packing and the sample scales is barely investigated and very few data are available to date. Such a scale concerns the coherent domains and therefore is positioned in between the nano- and the microscopic scales. In crystallography, data obtained at this physical scale are called microstructural properties.

Figure 1. Schematic overview of the different physical scales addressed by the



spin crossover within a molecular crystal including the associated main impacted features and the time-scale of the phenomenon. Compiled and adapted from $[2 b, 3,5]$. The results presented here concerned the coherent domain physical scale.

Any crystalline sample is built by a mosaic of coherent domains, i.e. the volume truly containing a unique periodic atomic assembly. If the coherent domains are large and almost perfectly aligned within the solid then the sample is a single-crystal and if the coherent domains are very small $(<\mu \mathrm{m})$ and misaligned then the sample is a crystalline powder. The description of the coherent domains is mainly accessible from the Bragg peak morphology in X-ray diffraction experiments. ${ }^{[6]}$ We have recently reported a study of the coherent-domain scale in a molecular SCO single

[a] CNRS, Univ. Bordeaux, ICMCB, UPR 9048, 87 avenue du Dr A.

Schweitzer, F-33608 Pessac, France

E-mail: philippe.guionneau@icmcb.cnrs.fr

http://www.icmcb-bordeaux.cnrs.fr/2

http://www.u-bordeaux.fr/ 
crystal. In such case it was referred to the notion of mosaicity that measure the misalignment of the coherent domains within the sample. The increase of the mosaicity showed that the investigated sample suffers from a structural fatigability at the level of the coherent domains over a repetitive sequence of SCO. ${ }^{[7]}$ In order to proceed on the investigation of this physical scale and to explore a SCO sample in a form probably closer from the applicative one, we present here the first study of the coherent domains morphology in a powder including the effect of a large number of repetitive SCO thermal cycles.

The selected powder sample for this study is known as one of the most promising compound for applications since it shows a SCO with a wide hysteresis $(\approx 30 \mathrm{~K})$ above the room temperature $\left(\mathrm{T}_{1 / 2}=\right.$ $346-375 \mathrm{~K}){ }^{[8]}$ It is the 1D-polymeric iron(II) compound of formula $\left[\mathrm{Fe}(\mathrm{Htrz})_{2}(\mathrm{trz})\right]\left(\mathrm{BF}_{4}\right) \quad(\mathrm{Htrz}=1 H-1,2,4$-triazole and $\operatorname{trz}=$ deprotonated triazolato(-) ligand) widely studied in the SCO scientific community since a few decades. ${ }^{[8-9]}$ The crystal structure has been determined only recently, confirming a crystal packing based on infinite $\left[\left(\mathrm{Fe}(\mathrm{Htrz})_{2}(\mathrm{trz})\right)\right]^{+}$chains linked together through interactions mediated by the anions and hydrogen bonding. ${ }^{[10]}$ The crystal structure determination has also revealed that this sample shows the largest known packing expansion associated to the SCO $\left(\Delta \mathrm{V}_{\text {unit-cell }}=10 \%\right)$. One of the key point of this compound within the 1D polymeric $\mathrm{Fe}(\mathrm{II})$ triazole-based family of SCO materials is that the synthesis is perfectly reproducible and that there is neither polymorphism nor various degrees of hydration, the whole leading to a very stable powder. Elsewhere, note that it has been previously shown that for this compound the crystal structure is the same whatever the particle size at least in the range $[10 \mathrm{~nm}-\mathrm{a}$ few $\mu \mathrm{m}] .^{[10]}$ The present study concerns this range of particle size and indeed all registered diffraction patterns displayed no significant structural change at the scale of the crystal packing.

\section{Results and Discussion}

\section{Coherent domains vs crystal packing and particle size}

The coherent domain morphology obtained for the studied powder at $300 \mathrm{~K}$ (LS) is shown on Figure 2. The calculation methodology is described below in the experimental part. The coherent domains adopt the form of an elongated stick with its long axis corresponding to the $\underline{b}$ crystallographic unit-cell axis. One can already note the coherence of this result since the $\underline{b}$ axis is also the direction of elongation of the $\left[\mathrm{Fe}(\mathrm{Htrz})_{2}(\operatorname{trz})\right]^{+}$chains within the crystal packing. ${ }^{[10]}$ The coherent domain morphology reflects therefore the growing of the chains along their axis during the crystallization process. The average three dimensions of the coherent domain are $530 \mathrm{~nm}$ along $\underline{b}, 64 \mathrm{~nm}$ along a and $52 \mathrm{~nm}$ along $\underline{\mathrm{c}}$. It is worth noting that the a crystallographic direction mainly corresponds to the interaction between the chains mediated by the anion while the $\underline{c}$ direction corresponds to the direct interactions between the chains through hydrogen bonding. In the subsequent study the value obtained for the size of the coherent domain along the $\underline{c}$ direction is always the same, showing no variation over thermal treatment of the powder. This result confirms that the chains are indeed closely linked along this $\underline{c}$ direction. In the following, since the focus is done on the modifications of the coherent domain sizes, we thus discuss and represent the coherent domain sizes corresponding to the crystallographic $\underline{a}$ and $\underline{b}$ directions.

It is also worth to tackle the difference between the particle size and the coherent-domain size. The former can be seen by electronic microscopy while the latter is only reachable through diffracting techniques. A particle, even a nanoparticle, can contain a large number of coherent domains. A study performed previously on a similar compound to the one investigated here had compared the particle sizes to the coherent domain sizes. ${ }^{[11]}$ It was then evidenced that depending on the synthesis protocol, a particle of this compound can be made of a few units only or as much as $10^{6}$ coherent domains. In the present case the SEM image of our sample shows parallelepipedic blocks of a few hundreds of $\mathrm{nm}$ long (Fig 3). A closer look reveals that these blocks probably correspond to an assembly of elongated particles, almost fibers. The superposition of the coherent-domain morphology obtained here to the observed fibers reveals that in the present case the coherent domains and the particles are of the same order of magnitude. Incidentally, this observation also confirms that, in this compound, the axis of the particle corresponds to the $\underline{b}$ unit-cell parameter, i.e. the chains axis.

Figure 2. View of the coherent-domain morphology at $300 \mathrm{~K}$ (top) and

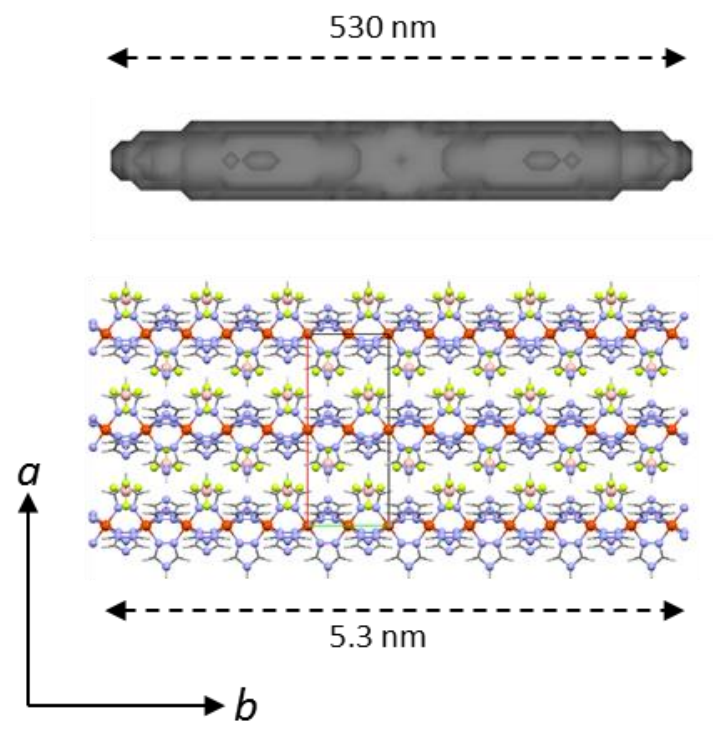

comparison with the crystal packing (down) showing that the axis of the domain is the iron-chain axis corresponding to the $\underline{b}$ unit-cell parameter. It is recorded that $\left[\mathrm{Fe}(\mathrm{Htrz})_{2}\left(\mathrm{trz}_{\mathrm{z}}\right]\left(\mathrm{BF}_{4}\right)\right.$ crystallizes in the orthorhombic Pnma space group with $\mathrm{a}=1.7347(2) \mathrm{nm}, \mathrm{b}=0.7324(1) \mathrm{nm}$ and $\mathrm{c}=0.9190(1)$ $\mathrm{nm}$ 


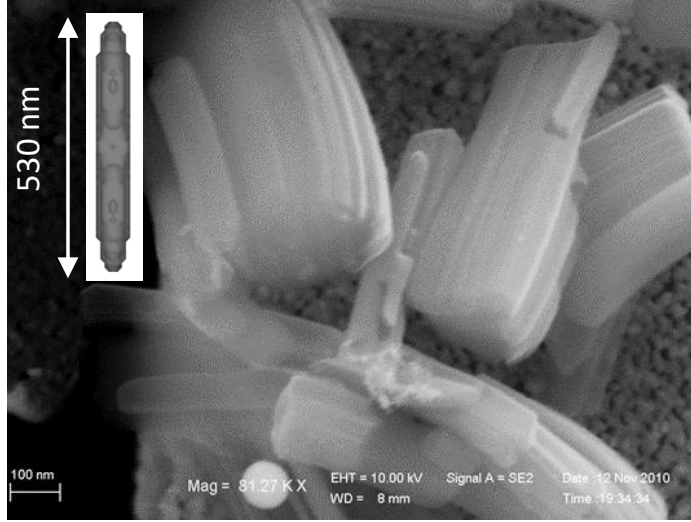

Figure 3. Superposition of a SEM image and of the calculated coherentdomain morphology for a $\left[\mathrm{Fe}(\mathrm{Htrz})_{2}(\operatorname{trz})\right]\left(\mathrm{BF}_{4}\right)$ powder showing the adequacy between the particle and the domain sizes. The SEM image is taken from reference [12].

\section{Evidence for a structural fatigability at the coherent- domain scale}

In order to investigate the potential effect of repetitive SCO on the coherent-domains morphology, the powder sample was submitted to temperature loops and then investigated at $300 \mathrm{~K}$. A thermal cycle consists to a loop going from $300 \mathrm{~K}$ (LS) to $420 \mathrm{~K}$ (HS) then to $300 \mathrm{~K}(\mathrm{LS})$; consequently the powder undergoes two SCO in one thermal cycle, hereafter called SCO cycle. The table 1 reports the unit-cell and the microstructural properties after three cycles and fifty cycles.

Table 1. Unit-cell parameters and microstructural data for $\left[\mathrm{Fe}(\mathrm{Htrz})_{2}(\mathrm{trz})\right]\left(\mathrm{BF}_{4}\right)$ at $300 \mathrm{~K}$ after SCO thermal cycles.

\begin{tabular}{cccc}
\hline $\begin{array}{c}\text { Number of SCO } \\
\text { cycle }\end{array}$ & $\mathbf{0}$ & $\mathbf{3}$ & $\mathbf{5 0}$ \\
\hline \multicolumn{2}{l}{ Unit-cell parameter $(\mathrm{nm})$} & & \\
$\mathrm{a}$ & $1.73401(4)$ & $1.72340(3)$ & $1.72289(3)$ \\
$\mathrm{b}$ & $0.73350(1)$ & $0.73388(1)$ & $0.73441(1)$ \\
$\mathrm{c}$ & $0.91885(2)$ & $0.91569(2)$ & $0.91686(2)$ \\
\hline Coherent domain sizes (nm) & & \\
along a & 64 & 56 & 56 \\
along b & $\mathbf{5 2 7}$ & $\mathbf{3 9 2}$ & $\mathbf{2 6 5}$ \\
along c & 52 & 51 & 51 \\
\hline Microstrains $\left(10^{-4}\right)$ & & & 18 \\
along a & 46 & 19 & 18 \\
along b & 21 & 17 & 24 \\
along c & 33 & 17 & \\
\hline
\end{tabular}

As already mentioned above, the size of the domains in the $c$ direction remains unchanged. With evidence, the number of SCO strongly affects the coherent domains sizes in the $\underline{b}$ direction since after only three cycles its length is shortened by about $25 \%$. After a larger number of SCO cycles (50) the coherent domain appears half sized. In parallel, the size along the a parameter is also affected by the three initial cycles $(-12 \%)$ but not by the subsequent ones. Consequently, successive SCO cycles seem to mainly affect the long axis of the domains (Fig. 4). This degradation reflects therefore a break of the $\left[\mathrm{Fe}(\mathrm{Htrz})_{2}(\operatorname{trz})\right]^{+}$ chains. Note that there is no indication either on the exact nature of this break or on its amplitude. It can correspond to a small

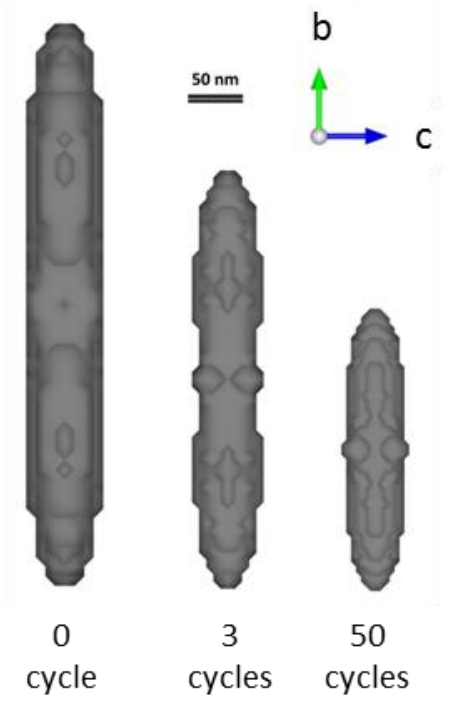

rotation of the chain or to a real break with translation of the chains. Anyhow, this significant modification of the coherent domain size clearly evidences a structural fatigability at the corresponding physical scale in this compound.

Note that the unit-cell is slightly modified by the three initial cycles but not significantly afterwards (Table 1). This means that the unitcell modification is not necessary linked to the domain size downfall since this one does not stop between the third and the fiftieth cycles. In the first cycles, the unit-cell modification affects the a unit-cell parameter corresponding to the inter-chain direction containing the anions. There is probably a small ordering of the anion along this direction. The decrease of the microstrains along the same a direction is on line with such assumption.

Figure 4. View of the break of the long axis of the coherent-domains as a function of the number of thermal cycles each corresponding to a HS-LSHS sequence in $\left[\mathrm{Fe}(\mathrm{Htrz})_{2}(\operatorname{trz})\right]\left(\mathrm{BF}_{4}\right)$. The long axis corresponds to the iron-triazole chains.

\section{Isotropic view of the microstructural fatigability}

The above approach allowing to get a 3D view of the coherent domain morphology is called an anisotropic approach. It is a timeconsuming approach that in addition necessitates very accurate diffraction patterns, not always achievable. In order to get in a reasonable time a large amount of data, an isotropic approach can also be performed. In such case the coherent domain is assimilated to a sphere and only one parameter, corresponding to the average diameter of the sphere, is extracted. Consequently, only an average size of the coherent domain is obtained. Obviously, in the case of a very anisotropic domain morphology, which is the case in the present study, the absolute meaning of this isotropic size is very weak. However, with the aim of comparison between different batches, the relative value can be meaningful. Therefore, to complete the above study we used an isotropic approach to investigate the coherent-domain size variation as a function of the number of SCO cycles. The isotropic 
size of the coherent domain was determined in this case after each thermal cycle from zero to fifty cycles (Fig 5a).

The isotropic value of the domain size must then be seen as an average of the three dimensions obtained above. Note however that the batch used for this experiment was not the same than the one used for the anisotropic determination, leading to different absolute coherent-domain values. Notwithstanding this point, the coherent-domain variation observed by this method confirms the structural fatigability (Fig. 5). The isotropic size variation as a function of the number of SCO cycles shows three different behaviors. In the course of the first cycle the size of the domain increases showing an improvement of the crystal quality. Then in the next ten cycles the modification is weak while from the cycles 10 to 50 the size strongly and continuously decreases showing a degradation of the crystal quality of the sample. There is no sign that this structural fatigability stops. Obviously investigations after 50 cycles are required to go further but in the hypothesis that this breakdown does not stop and follows the same line, one can roughly estimate that after 500 cycles the coherent domain is completely destroyed, leading to an amorphous compound. It is worth noting that in our study the magnetic properties are not significantly affected by this structural fatigability and the SCO temperatures are the same before and after the cycling process. One of the reasons is that even after fifty cycles, the coherent domains are still quite large in the present case despite the significant downfall. It had been previously shown that for $\left[\mathrm{Fe}(\mathrm{Htrz})_{2}(\operatorname{trz})\right]\left(\mathrm{BF}_{4}\right)$, the SCO temperature is almost unchanged down to particle sizes significantly smaller than the smallest reached in the present study, the exact particle-size limit being still debated. [9e-g] Undoubtedly when the coherent domains reach these very small sizes, the magnetic behavior should be checked. Clearly, this kind of investigations must be achieved in the context of an extensive exploration of the fatigability associated to the SCO, the present study being a pioneering step.

Taking advantage of this isotropic approach, a similar cycling experiment was performed on a compound of the same 1D polymeric SCO family, namely $\left[\mathrm{Fe}\left(\mathrm{NH}_{2} \mathrm{trz}\right)_{3}\right]\left(\mathrm{NO}_{3}\right)_{2} \cdot \mathrm{H}_{2} \mathrm{O}$ (Fig $\left.4 \mathrm{~b}\right)$. This compound presents SCO features comparable to the previous compound - an hysteresis width of $\approx 30 \mathrm{~K}$, SCO temperatures of $310-340 \mathrm{~K}$ - together with a close crystalstructure. ${ }^{[13]}$ Interestingly, like in the previous case the domain size increases in the course of the first SCO cycle, corresponding to an increase of the crystallinity. Such feature that could be a general trend can correspond to the crystallization of an amorphous part of the powder. In the subsequent cycles, the isotropic domain-size decreases very strongly. The collapse is continuous and shows no sign of stopping after 50 cycles. The amplitude of the breakdown is even much larger in this compound since it reaches $40 \%$ of the initial size. Consequently, like in the previous case, a structural fatigability at the coherent-domain physical scale is thus observed. It is more pronounced in this case and in the hypothesis it does not stop after 50 cycles and follow the same line, the coherent domains should be entirely destroyed before 200 cycles (400 SCO).
Figure 5. Variation of the isotropic domain size as a function of the number

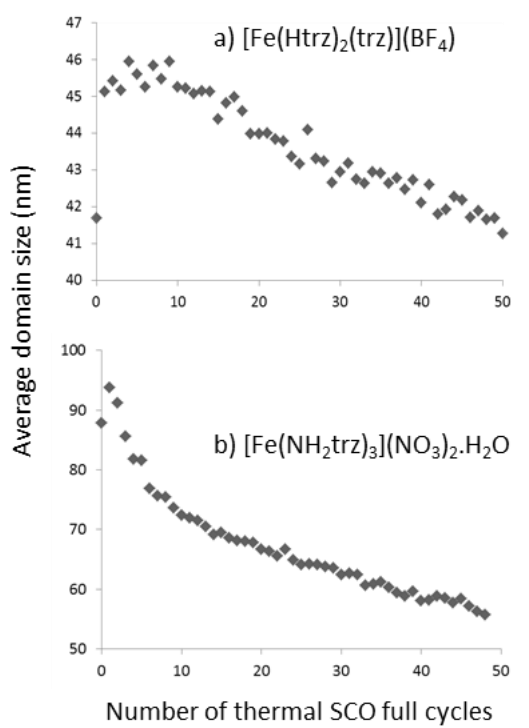

of SCO thermal cycles in the $1 \mathrm{D}$ polymeric SCO materials (a) $\left[\mathrm{Fe}(\mathrm{Htrz})_{2}(\mathrm{trz})\right]\left(\mathrm{BF}_{4}\right)$ and $(\mathrm{b})\left[\mathrm{Fe}\left(\mathrm{NH}_{2} \mathrm{trz}\right)_{3}\right]\left(\mathrm{NO}_{3}\right)_{2} \cdot \mathrm{H}_{2} \mathrm{O}$.

\section{Conclusions}

The morphology of the coherent domains in $\left[\mathrm{Fe}(\mathrm{Htrz})_{2}(\operatorname{trz})\right]\left(\mathrm{BF}_{4}\right)$ looks like a cylinder in agreement with both the known crystalpacking features and the particle shape. Clearly, the axis of the cylinder corresponds to the axis of the iron-triazole based chains. Elsewhere, a structural fatigability is observed at the scale of the coherent domains. It is clearly shown that a few hundreds of thermal SCO is susceptible to destroy the crystalline aspect of the material, i.e. leading to an amorphization. The same behavior is observed for $\left[\mathrm{Fe}\left(\mathrm{NH}_{2} \mathrm{trz}\right)_{3}\right]\left(\mathrm{NO}_{3}\right)_{2} \cdot \mathrm{H}_{2} \mathrm{O}$. It was already known that structural features at the crystal-packing scale can be possibly modified by aging in SCO compounds. ${ }^{[14]}$ In the present study, it is demonstrated that the coherent-domains scale can be affected by repetitive SCO. This result is different from the previous study on a molecular complex sample, i.e. exhibiting a OD network, since it also displayed a structural fatigability at the microscopic level but only for the first SCO cycles, the degradation being stopped after ten of cycles. ${ }^{[7]}$ The continuous degradation observed in the iron-triazole based compounds studied here could therefore be in relation with the 1D polymeric nature of these materials. As a general matter, the chain structure exhibited by these materials makes them peculiar in front of molecular SCO materials, as illustrated for example by some 1D triazole-based solids poorly crystalline showing yet abrupt SCO. ${ }^{[15]}$

The present work represents a very first insight in the notion of structural fatigability but it is clear that deeper and systematic investigations must be performed since the concerned family of SCO materials is often cited for potential applications. Note that the structural fatigability described here does not necessary affects the magnetic and optical properties associated to the SCO but it certainly must have repercussions on the mechanical 
properties, which could be crucial when dealing with the insertion of the SCO material inside a device for example.

\section{Experimental Section}

Synthesis. The powders of $\left[\mathrm{Fe}(\mathrm{H} \operatorname{trz})_{2}(\operatorname{trz})\right]\left(\mathrm{BF}_{4}\right)$ were prepared by micellar method. Two solutions were mixed, one of an iron(II) salt $\mathrm{Fe}\left(\mathrm{BF}_{4}\right)_{2} .6 \mathrm{H}_{2} \mathrm{O}$ $(2 \mathrm{mmol})$ in demineralised water $(1.6 \mathrm{~mL})$ with a small amount of ascorbic acid and one of the triazole in demineralised water $(1.6 \mathrm{~mL})$. The reverse micelles were then obtained by mixing each of those two solutions with the tergitol NP-9 (from the Nonylphenol Ethoxylate family), which played both the role of surfactant and organic solvent (the water-surfactant mass ratio was $75 \%$ ). The two resulting solutions were then heated to $80^{\circ} \mathrm{C}$ for 15 min and subsequently mixed and stirred for one hour. The compound was then extracted from the surfactant by using diethyl ether and washed several times. The powder of $\left[\mathrm{Fe}\left(\mathrm{NH}_{2} \mathrm{trz}\right)_{3}\right]\left(\mathrm{NO}_{3}\right)_{2} \cdot \mathrm{H}_{2} \mathrm{O}$ was prepared in a classical way. The solution of $\mathrm{Fe}\left(\mathrm{NO}_{3}\right)_{2}$ was prepared by mixing an aqueous solution $(2 \mathrm{~mL})$ of $\mathrm{FeSO}_{4} .7 \mathrm{H}_{2} \mathrm{O}(2 \mathrm{mmol})$ with a small amount of ascorbic acid to an aqueous solution $(5 \mathrm{~mL})$ of $\mathrm{Ba}\left(\mathrm{NO}_{3}\right)_{2}(1 \mathrm{mmol})$, the mixture being heated at $60^{\circ} \mathrm{C}$ and then the $\mathrm{BaSO}_{4}$ precipitate being filtered. An aqueous solution $(2 \mathrm{~mL})$ of $\mathrm{NH}_{2}$ trz $(6 \mathrm{mmol})$ was then added drop by drop to the solution of $\mathrm{Fe}\left(\mathrm{NO}_{3}\right)_{2}$. After 15 minutes stirring and four hours standing at $4^{\circ} \mathrm{C}$, the violet powder was filtrated, washed with ethanol and let dry at room temperature.

Powder X-Ray diffraction. Two kinds of measurements were performed for $\left[\mathrm{Fe}(\mathrm{Htrz})_{2}(\mathrm{trz})\right]\left(\mathrm{BF}_{4}\right)$. The first aimed to get high-resolution data for the determination of the 3D morphology of the coherent domains and the other one targeted the determination of the isotropic size dependence with the number of temperature cycles. High resolution data were recorded at $300 \mathrm{~K}$ by using a PANalytical X'Pert Pro diffractometer [Cu-Ka1, Ge (111) monochromator, X'Celerator detector, Flat-plate Bragg-Brentano geometry] within the range $8-50^{\circ}(2 \theta)$ using a scan speed of $0.5^{\circ}$ per hour. The sample holder was made of PVC to reduce the diffraction parasite peaks coming from the routine sample holders. Note that the same experimental configuration was previously used for the determination of the crystal structure. ${ }^{[10]}$ The 3D morphology was calculated for three batches coming from the same synthesis pot. The diffracting pattern of the first batch was recorded directly after the synthesis. Before recording the pattern of the second batch, three full SCO cycles were performed by heating the powder from 300 to $420 \mathrm{~K}$ then cooling to $300 \mathrm{~K}$. The third batch was submitted to fifty identical SCO cycles. An anisotropic Rietveld refinement of the coherent domain sizes and microstrains was performed for the three batches on the basis of the previously determined LS crystal structure. The refinements were performed and the 3D morphology visualized within the Fullprof Suite programs. ${ }^{[16]}$ Microstructural effects were treated using the Thompson-Cox-Hastings pseudo-Voigt profile function. ${ }^{[16 \mathrm{~b}]}$ The instrumental broadening was determined by measuring the Standard Reference Material SRM660a LaB6. The anisotropic strain broadening was modelled using a quartic form in reciprocal space. The anisotropic size broadening was modelled using spherical harmonics expansion of the crystallites shape. ${ }^{[16 c]}$ The isotropic study of the SCO cycling was performed on a powder coming from another synthesis pot than the previous one. Diffraction data were recorded by using a PANalytical X'Pert Pro diffractometer (Co-Ka, Fe $\beta$-filter, X'Celerator detector, Flat-plate Bragg-Brentano geometry) within the range $8-40^{\circ}(2 \theta)$ using a scan speed of $1.2^{\circ}$ per minute. The powder sample holder was made of alumina. An Anton Paar HTK1200 oven was used to cycle the powder from $300 \mathrm{~K}$ to $420 \mathrm{~K}$ at $100 \mathrm{~K} \cdot \mathrm{h}^{-1}$. The diffraction pattern was recorded after each cycle, until the fiftieth. The isotropic refinement was also performed with the Fullprof Suite programs. The investigation of the cycling effect on the isotropic coherent-domain size was performed on the same equipment and with the same procedure for $\left[\mathrm{Fe}\left(\mathrm{NH}_{2} \mathrm{trz}\right)_{3}\right]\left(\mathrm{NO}_{3}\right)_{2} \cdot \mathrm{H}_{2} \mathrm{O}$. In this case however the temperature loops were done between 300 and $380 \mathrm{~K}$ since the SCO is at slightly lower temperature than for $\left[\mathrm{Fe}(\mathrm{Htrz})_{2}(\operatorname{trz})\right]\left(\mathrm{BF}_{4}\right)$.

\section{Acknowledgements}

Acknowledgements are due to the Conseil Régional d'Aquitaine for the PhD grants of A.G. and L.M. The latter also thanks the ANR agency (project ANR-11-BS08-06) for partial funding of the PhD.

Keywords: spin crossover $\cdot$ microstructure $\bullet$ iron $\bullet$ triazole $•$ fatigability

[1] a) Spin-Crossover Materials: Properties and Applications, edited by M.A. Halcrow, 2013, John Wiley\&Sons; b) S. Hayami, S.M. Holmes, M.A. Halcrow, J. Mater. Chem. C 2015, 3, 7775-7778 and all included articles; c) P. Gütlich, A.B. Gaspar, Y. Garcia, Beilstein J. Org. Chem. 2013, 9, 342-391 ; d) A. Bousseksou, G. Molnár, L. Salmon, W. Nicolazzi, Chem Soc. Rev., 2011, 40, 3313-3335; e) K.S. Murray, H. Oshio, J.A. Real Eur. J. Inorg. Chem. 2013, 577-580 all included articles

[2] a) M.A.Halcrow, Chem. Soc. Rev. 2011, 40, 4119-4142; b) P. Guionneau, Dalton Trans. 2014, 43, 382-393; c) M. Shatruk, H. Phan, B.A. Chrisostomo, A. Suleimenova, Coord. Chem. Rev. 2015, 289, 62-73; d) T.M. Pfaffeneder, S. Thallmair, W. Bauer, B. Weber New J. Chem. 2011 $35,691-700$

[3] H. Cailleau, M. Lorenc, L. Guérin, M. Servol, E. Collet, M. Buron-Le Cointe, Acta Crystallogr., Sect. A: Fundam. Crystallogr. 2010, 66, 189197

[4] A. Slimani, F. Varret, K. Boukheddaden, C. Chong, H. Mishra, J. Haasnoot, S. Pillet, Phys. Rev. B 2011, 84, 094442(8)

[5] S. Matar, P. Guionneau, G. Chastanet, Int. J. Mol. Sci. 2015, 16, 40074027

[6] a) P. Scherrer, Nachr. Ges. Wiss. Goettingen Math.-Phys. Kl. 1918, 98 100; b) V. Uvarov, I. Popov, Mater. Charact. 2007, 58, 883-891; c) G. K. Williamson, W. H. Hall, Acta Metall. 1953, 1, 22-31 d) H. M. Rietveld, J. Appl. Crystallogr. 1969, 2, 65-71

[7] P. Guionneau, S. Lakhloufi, M.H. Lemée-Cailleau, G. Chastanet, P. Rosa C. Mauriac and J.F. Létard, Chemical Physics Letters, 2012, 542, 52-55

[8] a) J.G. Haasnoot, G. Vos, W.L. Groeneveld, Z. Naturforsch 1977, 32b 1421-1430; b) O. Kahn, J. Kröber, C. Jay, Adv. Mat. 1992, 4, 718-728 c) J. Kröber, J. P. Audière, R. Claude, E. Codjovi, O. Kahn, J.G. Haasnoot, F. Grolière, C. Jay, A. Bousseksou, J. Linarès, F. Varret, A. GonthierVassal, Chem. Mater. 1994, 6, 1404-1412

[9] a) G. Aromi, L.A. Barros, O. Roubeau, P. Gamez, Coord. Chem. Rev. 2011, 255, 485-546; b) L. G. Lavrenova and O. G. Shakirova, Eur. J. Inorg. Chem. 2013, 670-682; c) O. Roubeau, Chem.-Eur. J. 2012, 18, 15230-15244; d) P. Durand, S. Pillet, E. Bendeif, C. Carteret, M. Bouazaoui, H. El Hamzaoui, B. Capoen, L. Salmon, S. Hébert, J. Ghanbaja, L. Arandah, D. Schaniel, J. Mater. Chem. C 2013, 1, 19331942 ; e) E. Coronado, J. R. Galán-Mascarós, M. Monrabal-Capilla, J. Garcia-Martinez, P. Pardo-lbañez, Adv. Mater. 2007, 19, 1359-1361; f) M. Gimenez-Marqués, M. Luisa Garcia-Sanz de Larrea, E. Coronado, $J$ Mater. Chem. C 2015, 3, 7946-7953 ; g) C. Bartual-Murgui, E. Natividad, O. Roubeau, J. Mater. Chem. C 2015, 3, 7916-7924.

[10] A. Grosjean, P. Négrier, P. Bordet, C. Etrillard, D. Mondieig, S. Pechev, E. Lebraud, J.-F. Létard and P. Guionneau, Eur. J. Inorg. Chem. 2013 796-802

[11] T. Forestier, A. Kaiba, S. Pechev, D. Denux, P. Guionneau, C. Etrillard N. Daro, E. Freysz, J.-F. Létard, Chem. Eur. J. 2009, 15, 6122-6130

[12] C. Etrillard, PhD Thesis, University of Bordeaux, 2011 
[13] a) L.G. Lavrenova, V.N. Ikorskii, V.A. Varnek, I.M. Oglezneva, S.V. Larionov, Koord. Khim. 1986, 12, 207-215; b) A. Grosjean, N. Daro, B. Kauffmann, A. Kaiba, J.-F. Létard, P. Guionneau, Chem. Commun. 2011 47, 12382-12384; c) M.M. Dîrtu, C. Neuhausen, A.D. Naik, A. Rotaru, L. Spinu, Y. Garcia, Inorg. Chem. 2010, 49, 5723-5736

[14] G.A. Craig, J. Sánchez Costa, O. Roubeau, S.J. Teat, G. Aromí, Eur. J. Inorg. Chem. 2013, 745-752

[15] O. Roubeau, J.G. Haasnoot, E. Codjovi , F. Varret, J. Reedijk, Chem. Mater. 2002, 14 (6), 2559-2566
[16] a) J. Rodríguez-Carvajal, Recent Developments of the Program FULLPROF, in Commission on Powder Diffraction (IUCr) Newsletter 2001, 26, 12-19; b) P. Thompson, D.E. Cox, J.B. Hastings, J. Appl. Cryst. 1987, 20, 79-83; c) M. Jarvinen, J. Appl. Cryst. 1993, 26, 527-531; d) K. Momma, F. Izumi, J. Appl. Cryst. 2011, 44, 1272-1276 
Entry for the Table of Contents (Please choose one layout)

Layout 1:

\section{FULL PAPER}

The coherent-domain morphology is determined in 1D polymeric spincrossover iron(II) based triazole materials. The break of the chains over a large number of thermal spin crossover is demonstrated.

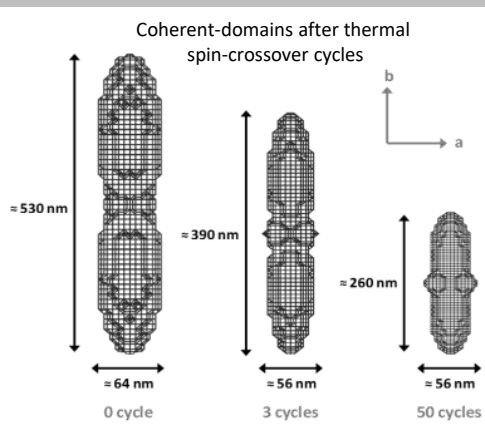

\section{Key Topic* Spin-crossover}

Author(s), Corresponding Author(s)*

Page No. - Page No.

Title 